\title{
Legitimidad democrática y derechos básicos: la ética del discurso como núcleo de una teoría democrática
}

\section{Democratic legitimacy and basic rights discourse ethics as the core of a democratic theory}

\author{
JAIRO MIGUEL TORRES OVIEDO \\ Abogado, magister y doctor en filosofía \\ Docente investigador de la Universidad Cooperativa de Colombia \\ jairom.torres@campusucc.edu.co \\ OONA ISABEL HERNÁNDEZ PALMA \\ Abogada, magister en derecho \\ Docente de la Universidad Cooperativa de Colombia \\ oona.hernandezp@campus.ucc.edu.co
}

Para citar este artículo

Torres Oviedo,J \& Hernández Palma,O (2015). Protección de los derechos económicos, sociales y culturales en el ordenamiento jurídico colombiano - el papel de los jueces. Justicia Juris, 11(1), 125-139.

Recibido: Noviembre 24 de 2014

Aceptado: 20 Marzo de 2015

\section{RESUMEN}

El propósito de este artículo es realizar una reflexión en el terreno de la filosofía política contemporánea, centrado en la Ética del Discurso del filósofo alemán Jürgen Habermas. La intención es mostrar que no solo la ciencia y la tecnología son actividades racionales; sino también el derecho. la moral y la política. Es decir, que así como en la ciencia, los sujetos se ponen de acuerdo en razones de verdad, también es posible que en el mundo social y alrededor de las ideas jurídicas, morales y políticas los sujetos puedan llegar a acuerdos basados en cuestiones de rectitud normativa que permitan construir procesos de modernización social. En este sentido la ética del discurso intenta clarificar o hacer explícito un concepto de razón dialógica, en donde esa razón dialógica haría posible la generación de procesos de legitimidad democrática sobre la base de procesos de entendimiento y sobre la base del diálogo.

Palabras clave: Legitimidad, democracia, ética, discurso, teoría.

ABSTRACT

The purpose of this article is to reflect on the terrain of contemporary political philosophy, whose object of reflection focuses on discourse ethics of the German philosopher Jürgen Habermas. The intention is to show that not only science and technology are rational activities; but also the right morals and politics. That is, that as in science, subjects agree on matters of truth, it is also possible that in the social world and about the legal, moral and political ideas subjects can reach agreements based on issues of righteousness rules that allow the construction processes of social modernization. In this regard discourse ethics attempts to clarify and make explicit a concept of dialogical reason dialogical where that reason would generate processes of democratic legitimacy based on processes of understanding and on the basis of dialogue possible.

Keywords: Legitimacy, democracy, ethics, discourse theory. 


\section{Formalidad y legitimidad política}

En esta línea de discusión Habermas y Apel hacen la distinción entre consenso racional y empírico precisando que "la mayoría de los procesos de formación del consenso son solo empíricos" (Cohen, 2000, pág. 398). La mayoría de los consensos son empíricos debido a que las normas del discurso, las cuales garantizan su validez, no son el producto de los acuerdos; sino el resultado de las condiciones de posibilidad de los acuerdos válidos; es decir, entran a jugar un papel determinante en esos acuerdos, los intereses, las coacciones, las manipulaciones; en otras palabras las acciones estratégicas.

Por ello, es necesario seguir apostándole a procesos de aprendizaje que haga posible el uso de la comunicación como mecanismo esencial de la convivencia. En este sentido Habermas agrega que:

Los conflictos proceden de perturbaciones de la comunicación, de malas interpretaciones e incomprensiones, de la insinceridad y el engaño. La espiral de la violencia comienza con una espiral de comunicación perturbada, que conduce a una ruptura de la comunicación a través de la espiral de una desconfianza reciproca incontrolada. Pero si la violencia comienza con la perturbación de la comunicación, se puede saber qué ha ido mal y qué debe repararse tras el estallido (Habermas, 2009, pág. 24) .

En los términos expuestos por Habermas, lo anterior, es un asunto mucho más complejo, por cuanto existen relaciones sociales de la vida cotidiana que son mucho más cercanas, que se ven permanentemente distorsionadas y se restablecen a través de la comunicación.

Con relación a este aspecto, es necesario decir al tenor de Adela Cortina que:

Tanto Apel como Habermas coinciden en aceptar el giro lingüístico en la filosofía y en las ciencias sociales, y lo aceptan desde un punto de vista hermenéutico y pragmático; es decir, tratando de acceder a la relación entre los sujetos que hacen la ciencia y la historia. Este procedimiento les lleva a descubrir ese modo de racionalidad humana al que llamamos racionalidad comunicativa, discernible de la racionalidad instrumental porque la primera descansa sobre el esquema sujetoco-sujeto, y la segunda tiene su base en la relación sujeto-objeto (Adela, 1985, pág. 86).
La relación entre sujeto-co-sujeto es una relación de carácter intersubjetivo que tiene como finalidad la construcción del entendimiento o acuerdos recíprocos (verstandigung) este tipo de proceso deben ser una actitud indispensable entre los seres humanos, que haga posible la comprensión. Podemos inferir que la reflexión hermenéutica y pragmática alrededor del lenguaje posibilita la superación del objetivismo y en consecuencia sino existe acuerdo entre los hombres, no es posible la construcción o existencia del conocimiento. Por ende, es necesario afirmar sin sonrojarnos, que la razón humana ha sido y es permanentemente dialógica. Ahora bien, nos referimos a la necesidad del diálogo, como una característica esencial de la racionalidad humana.

En este sentido, Habermas reformula el imperativo categórico kantiano orientado por medio del procedimiento argumentativo.

En vez de prescribir a todos los demás como válidas una máxima que yo quiero que sea una ley general, tengo que ofrecer mi máxima a todos con el propósito de comprobar discursivamente su pretensión de universalidad. El énfasis se desplaza de lo que cada uno puede desear sin contradicción que sea una ley general, a lo que todos pueden desear, puestos de acuerdo, que sea una norma universal (Cohen, 2000, pág. 399).

La idea de un consenso racional va más allá de la participación de los afectados en la discusión de una norma relevante;

Lo realmente importante en este proceso es que la legitimidad de la norma nos indique que es correcta para una determinada situación y que no simplemente el acuerdo al que se llegue sea solamente una sumatoria de voluntades. Habermas insiste en que la ética del discurso, al igual que toda ética cognitiva, supone que las pretensiones de validez normativa tienen significado cognitivo y que pueden ser manejadas, con ciertos ajustes, como pretensión de verdad cognitiva (Cohen, 2000, pág. 399).

El hecho que una determinada comunidad le de reconocimiento a una norma, es un indicador de que la norma puede ser válida. Su validez se determina empleando un principio articulador, entre la voluntad y la aceptabilidad de una determinada norma, y ese principio articulador es la ética del discurso. 
En cuanto al contenido formal de los acuerdos, que es el segundo aspecto al que alude la ética del discurso, Habermas sostiene "que para ser objetivas (unparteilich), racionales y legítimas, las normas de acción en las que estamos de acuerdo deben expresar un interés generalizable (Habermas j. , 1999, pág. 108). En consecuencia, toda norma válida debe satisfacer la siguiente condición: "todos los afectados pueden aceptar las consecuencias y los efectos laterales que se anticipa tendrá su cumplimiento general para la satisfacción de los intereses de todos (y estas consecuencias son preferibles a las de posibilidad alternativas de regulación)" (Habermas, j.1999, pág. 65). Luego entonces, el principio de universalización necesita de discursos reales que permita que los involucrados puedan discutir sobre aspectos en los que todos pueden estar de acuerdo y reconocer como válido.

Por lo tanto, Habermas sostiene "que como principio de legitimidad, la ética del discurso puede resolver la aparente separación entre legalidad y moralidad al revelar la ética política que subyace a la ley (Cohen, 2000, pág. 400)"1. En este contexto en donde es necesario preguntar, ¿si la ética del discurso es una teoría de la moralidad o una teoría de la legitimidad política?

Este es el escenario teórico y conceptual donde moveremos la ética del discurso, como referente teórico y metodológico válido en los procesos de legitimación democráticas; igualmente se puede interpretar la ética del discurso como un proyecto tendiente a aunar esfuerzos que permita utilizar los aportes de la teoría ética deontológica; que le haga frente al positivismo legal, al igual que a la teoría de sistemas de Luhmann. En síntesis, el propósito es mostrar la existencia de un componente de legalidad y de política, que se puede defender normativamente y racionalmente. Ahora bien, el anterior propósito es independiente de las sanciones empíricas que se presenten. Por consiguiente, lo que pretende la ética del discurso, es explicar la 1 Para decirlo de otra manera, la ética del discurso de Habermas puede ser considerada como un esfuerzo "posthegeliano" para unir al principio liberal de los derechos básicos (y a la concepción de la libertad negativa) y la antigua concepción republicana (y de inicio de la modernidad) de la libertad positiva dentro de la estructura de una teoría que presupone la diferenciación. A diferencia del modelo hegeliano, sin embargo, la teoría de la ética del discurso no nos lleva a construir la concepción normativa de la política (o los principios normativos que subyacen en la ley) en términos de una concepción monista, sustantiva y en última instancia no democrática de la vida ética. En cambio, como una teoría de la legitimidad democrática, la ética del discurso hace posible concebir una nueva forma de libertad pública adecuada a una pluralidad de formas de vida, que presuponen y en parte justifica el principio de los derechos básicos. obligatoriedad de las normas legales y la legitimidad de un determinado sistema social y político. $Y$ es precisamente en este aspecto es donde toma relevancia el principio discursivo expuesto en la ética del discurso.

\section{Relación de la ética del discurso con las institu- ciones democráticas}

Luego de establecer el límite o diferenciación entre la teoría moral general y la teoría de la legitimidad política; se puede plantear el siguiente interrogante ¿cómo se ubica el límite entre las dos? Al respecto podemos decir que este límite esta mediado por distintos puntos de vista y enfoques que apuntan a diferenciar cada uno de estos ámbitos. Cuando se definen limites que diferencien las esferas privadas y públicas. En este mismo orden de ideas, es importante precisar que este enfoque de diferenciación es infuncional, por cuanto el entendimiento que tienen los miembros de una sociedad de los acuerdos institucionales, va más allá de lo normativo en términos jurídicos y si se deja al juicio de los individuos, es cambiante con el paso del tiempo. Igualmente la designación de privado respecto a las instituciones y a las relaciones, no la exime de satisfacer las demandas de justicia sino que, más bien, implica una forma diferente de regulación legal-normativa" ${ }^{2}$.

Cuando se habla de lo público y lo privado, se debe dejar en claro que lo público hace referencia al ámbito de lo regulado legalmente y al que tienen acceso todos sin condicionamientos; por su parte lo privado tiene que ver con todo aquello que corresponde a la elección moral o al juicio personal de las personas, en este sentido la vida privada le permite a los individuos el desarrollo de ciertas capacidades como son: la condición de sujeto moral autónomo, amistad, intimidad e identidad. Estos asuntos, referidos a la esfera privada deben ser defendidos y respetados por las instituciones sociales; por ello, en los estados de derechos hacen parte

2 Para una crítica de la dicotomía público/privado siguiendo estas líneas, véase Sussan Okin, justice, Gender and the Family, Nueva York, Basic Books, 1989. Okin pone en duda el supuesto de que como la familia es un "espacio privado", se encuentra "más allá de la justicia". Convincentemente argumenta que las "circunstancias de la justicia "discutidas por Hume y Rawls se presentan en la familia: Los esposos, las esposas y los hijos tienen tantos intereses comunes como diferentes. Por lo tanto, todos los miembros de la familia pueden afirmar sus derechos. Nuestra inclusión de la familia en la sociedad civil está de acuerdo con este argumento. Por supuesto, la ley familiar difiere de la ley contractual o administrativa, pero "esta esfera privada" está a pesar de todo regulada legalmente, incluso cuando ciertas decisiones dentro de la misma sean consideradas privadas. 
de los derechos fundamentales e inalienables y por lo tanto gozan de las garantías y protección del estado para su ejercicio. En este orden de ideas, y en aras de respetar la esfera privada, las leyes se convierten en algo así como factores de autolimitación respecto a los juicios individuales o autónomos de los sujetos; claro está, siempre que estos no impliquen la violación de derechos fundamentales. De aquí, que este sea un tema de preocupación y ocupación académica para Habermas, y es el tratar de dirigir o conciliar el interés individual con los grupales, tratando de devolverle la dimensión moral a la política desde una visión racional.

Desde este punto vista, Cohen y Arato sostiene que la interpretación de la ética del discurso como una teoría de la legitimidad democrática y de los derechos básicos presupone la percepción sociológica que se refiere a la "positivización de la ley y la correspondiente separación entre las esferas de la legalidad y de la moralidad. No obstante, nuestra versión de la teoría rechaza el punto de vista de que la desnormativización total de la política o de la ley y la despolitización de la moralidad son las consecuencias inevitables de este proceso" (Cohen, 2000, pág. 402).

De acuerdo a Habermas, esto muestra la manera como el desarrollo de una moralidad universalista autónoma, al igual que el surgimiento de un sistema normativo de carácter positivista; han sido un ejemplo claro de progreso histórico de la humanidad en términos de ética, moral y derecho. Estos aspectos que han configurado parte del progreso social y humano, es lo que ayudo a configurar la existencia de los sistema democráti$\cos$, al mismo tiempo que las sociedades modernas y los sistemas constitucionales; sobre la cual se levanta el concepto moderno de sociedad civil. Pero igualmente surgen otros aspectos en este proceso tales como:

La separación de las normas legales positivas del campo de la moralidad privada con base en los principios que acompañaron la emergencia de los estados constitucionales y de las economías de mercado capitalistas supone un conflicto potencial entre la lealtad del ciudadano a las reglas abstractas del sistema legal (que solo son válidas para el área pacificada por un estado particular) y el "cosmopolitismo del ser humano", cuya moralidad personal presenta exigencias generales (Habermas j. , 1999, pág. 87).

Lo anterior, ha puesto de manifiesto la diferenciación entre legalidad y moralidad ha implicado tanto la separación de la política de la vida diaria de los ciudadanos como la desnormativización de la propia legalidad, al menos según una buena parte de la teoría legal desde el siglo XIX" (Habermas j. , 1999, pág. 89)33.

Por consiguiente, las normas jurídicas han de poseer una dimensión fáctica que les permita por un lado su cumplimiento normal y por el otro, la coacción que las sustenta; en este contexto aparece la función de integración social que tiene el derecho en sociedades complejas ya que en estas sociedades ya no es suficiente para la integración los aspectos mítico-religiosos o metafísicos en las que se soportaban las normas como factor común y compartido, si no de la aceptación, la cual genera una legitimidad que supera su pura imposicióncoacción. Toda norma es legítima independiente de su imposición fáctica y más bien, la legitimidad de una norma dependerá de la forma en que es creada. García Amado, indica que

Son legítimas cuando sus destinatarios pueden al mismo tiempo sentirse, en su conjunto, como autores racionales de esas normas, es decir, cuando el procedimiento de creación de las normas reproduce el procedimiento argumentativo y consensual de la razón comunicativa; o dicho de otro modo, cuando se sigue el procedimiento democrático sin distorsiones" (Garcia Amado, 1999, pág. 19).

Este procedimiento de carácter argumentativo garantiza al mismo tiempo la legalidad de la conducta, como la legitimidad de las reglas. Y es esto precisamente, uno de los aspectos centrales que propone Habermas en su libro de facticidad y validez. En este punto, quisiera hacer la siguiente anotación, con respecto a la función de integración social del derecho, función esta que debe llevarse a cabo en ordenamientos jurídicos legítimos; por cuanto, la construcción de las normas en las sociedades democráticas modernas deben emanar de un proceso legislativo de carácter democrático; de lo contrario esas normas no serían cumplidas por las mayorías de los miembros de una sociedad y en consecuencia el orden social estaría en crisis y el derecho no cumpliría su función de cohesión social.

En su debate con Weber y Luhmann respecto a los fundamentos de la dominación legal-racional, "Habermas repetidamente ha indicado la impo-

3 Habermas específicamente se refiere a la versión que presenta Weber de esta tesis. 
sibilidad de derivar la legitimidad de un sistema legal moderno como un todo únicamente de la formalidad y naturaleza sistémica de los procedimientos legales" (Habermas j. , 1999, págs. 95-117). En este sentido Cohen y Arato sostienen que:

La ley como autoridad legítima se basa en fuentes extralegales de justificación. Las referencias a las constituciones como la fuente última de autoridad, al menos por parte de los estados formalmente democráticos, implican que la legitimidad de la ley en última instancia depende los principios de la democracia y de los derechos básicos-incorporados a las constituciones y en los procesos democráticos que supuestamente están detrás del desarrollo de las constituciones" (Cohen, 2000, pág. 403).

Es obvio que estos principios de legitimidad democrática y derechos básicos hacen parte de la esencia de cualquier sistema jurídico, aunque hoy, no son principios absolutos, como lo fueron en las épocas de las teorías del derecho natural y en las teorías republicanas de la virtud cívica. Precisamente, por no ser principios absolutos. En este escenario es donde la competencia de la ética del discurso se puede convertir en el referente teórico que suministre un equivalente a esas teorías.

En este orden de ideas, se reinterpreta la ética del discurso por un lado como un principio de legitimidad democrática y por otra parte como una teoría de los derechos básicos. De esta forma:

La ética del discurso tiene un status doble: su dominio objeto especifico comprende relaciones sociales institucionalizadas, el sistema político y legal como un todo, y las leyes y derechos particulares. En otras palabras, es sólo después de que se han discutidos públicamente cuestiones debatibles cuando podemos decidir qué es lo que debe ser considerado "privado", esto es dejarse a la determinación del juicio autónomo del individuo respecto a un ideal personal de la vida buena" (Cohen, 2000, pág. 401) ${ }^{4}$.

4 Aquí es necesario una aclaración: Habermas presenta a la ética del discurso como una teoría moral general. Al hacerlo así, distingue entre el punto de vista moral (el derecho) y los asuntos de identidad individual o de grupo, o de sistema de valores culturales (el bien). Su propia versión de la dicotomía público/ privado se refiere así a la distinción entre los principios morales universalistas (públicos) y los valores particulares que una persona considera en su forma de vida, necesidad de identidad, plan de vida, etc.
En este aspecto, surge un problema de aceptabilidad en cuanto a que los que se definen en un proceso discursivo pueden ser o no ser aceptados desde las concepciones morales y de identidad de las personas o colectivos sociales. “Una mayoría podría tratar de regular legalmente áreas de la toma de decisiones que previamente habían sido consideradas privadas y que una minoría no desea someter a esa regulación. La objeción consciente y la desobediencia civil son opciones legítimas desde el punto de vista moral" (Cohen, 2000, pág. 405). Por ello, cuando estas situaciones se presentan en la convivencia social, requiere de la acción de la justicia en el sentido que ninguna persona puede ser obligada a renunciar a sus formas de vida, identidad, dignidad y convicciones morales, políticas, ideológicas o religiosas.

Luego entonces, frente a estas situaciones, es prioritario recurrir a la conciencia moral de los individuos, como un factor auto limitante, que permita hacer uso del principio de la legitimidad democrática y los derechos fundamentales; que posibilite el ejercicio público y democrático de las diferencias.

Esto significa que, en el caso de conflictos entre las concepciones de la vida buena y la legalidad, no debe considerarse antiético que el individuo siga su conciencia o juicio moral y actúe de conformidad con él. No obstante, uno debe actuar según los dictados de la autolimitación. Dentro de la estructura de una forma de organización política constitucional democrática, una violación legítimamente moral de la ley presupone el conocimiento de principios constitucionales, la aceptabilidad del orden democrático y una orientación simbólica de la acción para influir en la opinión pública y desarrollar un nuevo consenso normativo (Cohen, 2000, pág. 410) .

En este punto se tiene que hacer claridad, puesto que no se tratan de acciones criminales que afectan la vida humana, si no que por el contrario, este tipo de acciones enmarcadas en el ámbito discursivo, lo que pretende es buscar entendimiento y acuerdos desde las diferencias morales o políticas; acuerdos que puedan alcanzar la legitimidad moral y jurídica suficiente para tener aceptabilidad entre las personas o miembros de un grupo social. En este sentido, "el principio básico de la ética discursiva toma pie en un procedimiento, esto es, la comprobación discursiva de las pretensiones normativas de validez. A este respecto cabe calificar con razón la ética discursiva de formal. Esta no ofrece orientación de contenido alguno, sino un procedimien- 
to: el del discurso práctico. Este es, en realidad, un procedimiento no para la producción de normas justificadas, sino para la comprobación de la validez de normas propuestas y establecidas con carácter hipotético" (Habermas J. , 2010, pág. 128), entonces se observa el principio formal de la ética del discurso, no solo para legitimar procedimientos normativos o morales, sino como una posibilidad para resolver conflictos de carácter general que se presenten en la sociedad.

...Cuando definimos las cuestiones prácticas como cuestiones de la "vida buena", que se refieren en cada caso a la totalidad de una forma de vital particular o a la totalidad de una forma vital particular o a la totalidad de una biografía particular, el formalismo ético es, en efecto, decisivo (Habermas J. , 2010, pág. 129).

El principio discursivo de la ética del discurso y su carácter de universalidad permite hacer una distinción entre lo bueno y lo justo. Por consiguiente el principio discursivo de la ética del discurso se convierte en una especie de meta norma que presupone la autonomía de la conciencia moral del individuo.

De esta forma,

las propias reglas que subyacen al argumento y a la búsqueda cooperativa del consenso implican una distinción entre moralidad y legalidad. Al articular las metas normas del principio de legitimidad democrática y de algunos derechos claves, la ética del discurso presupone la justificación de la autonomía de la esfera moral y, por decirlo así, su propia autolimitación (Cohen, 2000, pág. 406).

Por otra parte, hay razones suficientes para justificar que ningún consenso,

sin importar lo unánime o perdurable que sea, puede ser considerado en si como permanente, porque no hay ninguna coincidencia automática entre lo justo y lo moral, entre lo que es considerado correcto normativamente en un momento determinado para una comunidad solidaria y lo que siempre es aceptable moralmente para cada individuo (Cohen, 2000, pág. 406).

Por cuanto las normas discursivas por muy idealizadas que estén, chocan con los interés individuales o valores particulares y de identidad. De esta manera, es importante destacar que cuando la norma jurídica ha resistido los procesos discursivos, no quiere decir, que esté exenta de los conflictos que generan los valores individuales o exigencias de identidad de las personas.

Ni la autonomía moral ni la identidad in-
dividual pueden sacrificar a una identidad
colectiva o al consenso de un grupo, porque
esto violaría la misma raisond'etre de la éti-
ca del discurso: proporcionar un principio
formal para la legitimidad de las normas en
una sociedad que es plural y está integrada
por individuos con concepciones distintas y
diferentes de la vida buena. Incluso en una
situación que se acerque mucho a los reque-
rimientos de reciprocidad simétrica, no hay
ninguna base para suponer ni la ausencia de
la diferencia ni la ausencia del cambio. Todo
consenso es, después de todo, sólo empírico
y debe quedar abierto al desafío y a la revi-
sión (Cohen, 2000, pág. 406 ).

Es posible desde el punto de vista de la justicia que los valores que identifican a una minoría hoy se conviertan en valores colectivos posteriormente, en esto consiste precisamente el consenso, por cuanto permite consensuar las diferencias y pluralidades, ofreciendo autonomía necesaria para su validez. Por ello, es importante precisar lo planteado por Habermas cuando dice que:

Cuando la moral en cierto modo se vuelve
autónoma y en las sociedades de nuestro
tiempo ya no puede apoyarse sin más en la
eticidad sustancial de deberes tradicionales,
es decir, ni en la religión, ni tampoco en las
costumbres, entonces sobre los débiles hom-
bros de la persona individual empieza a pe-
sar una carga nada desdeñable. Pues con la
simple idea de que el deber no puede con-
sistir en otra cosa que en actuar conforme a
aquello que sea en interés de todos por igual,
no se ha ganado todavía mucho para la prác-
tica (Habermas J. , Más allá del estado nacio-
nal, 1998, pág. 97).

En consecuencia, el derecho positivo se convierte en un complemento indispensable de la moral, la que se sitúa de manera definitiva en la conciencia subjetiva. El mismo Habermas establece que:

El orden jurídico del Estado Constitucional democrático encarna un contenido moral, pero para la realización de ese contenido de sus principios ya no depende de la buena 
voluntad de los destinatarios. Ahora bien, el procedimiento democrático de la legislación, que es el que empieza convirtiendo a los destinatarios del derecho en autores de él, si depende de una ciudadanía activa, es decir, depende de motivos que no cabe imponer por medio del derecho. Por tanto, las instituciones del Estado de derecho se nutren del contexto de comunicación que representan espacios públicos políticos y tradiciones liberales que el sistema jurídico no puede hacer surgir por su propia fuerza (Habermas J. , Más allá del estado nacional, 1998, pág. 98).

En esto toma relevancia el papel de la sociedad civil organizada y deliberativa, pero sobre todo la existencia de una sociedad liberal que haga posible el ejercicio de las libertades negativas. Precisamente, frente a una sociedad liberal altamente diferenciada y plural es donde tiene sentido hablar de una integración normativa. En este sentido Habermas nos dice que:

El punto de vista moral se esconde ya en la estructuras de las acciones comunicativas simples, en las que nos reconocemos mutuamente como susceptibles de que se nos atribuyan nuestros actos, a la vez que como personas vulnerables y necesitadas de protección. Nos podemos representar el derecho como una correa de transmisión mediante la cual las estructuras de reconocimiento reciproco que nos resultan conocidas por situaciones concretas quedan transferidas a relaciones abstractas entre extraños (Habermas J. , Más allá del estado nacional, 1998, pág. 98).

El derecho no puede desconocer a la moral, especialmente frente a situaciones complejas. Un caso concreto frente a esta situación son los fallos judiciales: Un juez cuando aplica el derecho tiene que tener en cuenta razones éticas y morales en el entendido de que el derecho positivo tiene sus características propias y su lenguaje especifico, pero en ningún momento puede ser entendido como neutral en lo concerniente a asuntos morales.

Por lo general, el problema de la exigibilidad de una acción moralmente mandada solo se plantea en el paso de la teoría moral a la teoría del Derecho. En el moderno Derecho racional, son explicitas consideraciones de exigibilidad las que marcan el paso de la moral al derecho. A la luz del principio moral las normas se privilegian como válidas solo bajo la condición de una praxis de se- guimiento universal de esas normas. Si esta condición no se cumple, las normas no son exigibles, con independencia de su validez. Así es como justifica Kant el monopolio estatal del ejercicio de la coacción jurídica. Solo una institucionalización jurídica puede asegurar el cumplimiento universal de las normas moralmente válidas (Habermas.jurgen, 2000, pág. 204).

Cuando se fundamentan normas jurídicas determinadas, dicha fundamentación se desprende de posiciones morales; y es en este aspecto, donde el ejercicio legislativo que se realiza al momento de hacer las leyes debe tener en cuenta; por cuanto en lo que respecta a las normas jurídicas los asuntos de fundamentación deben diferenciarse de los asuntos de aplicación. Por consiguiente el mismo Habermas va a decir que:

De esta manera se va dibujando los perfiles del Estado de Derecho que Kant, con toda consecuencia, trata en las doctrinas del derecho; ahí el punto de vista moral ya no se aplica directamente a modos de actuar, sino a instituciones jurídicas y políticas. Las consideraciones desde la teoría del Derecho se pueden llevar finalmente hasta el punto en el que se plantea el problema clásico de los límites de la obediencia al Derecho, esto es, de las condiciones de la desobediencia civil y de la resistencia legitima, del "derecho a la revolución". Nos encontramos en esos casos ante condiciones bajo las cuales una trasgresión del Derecho positivo motivada políticamente puede estar moralmente justificada o ser legitima (Habermas.jurgen, 2000, pág. 205).

Las relaciones entre moral, derecho y política se pueden entender y explicar desde la teoría discursiva. En este mismo orden de ideas vale aclarar que "para los fundamentos de una teoría moral, de una teoría filosófica o de una teoría de la justicia es importante realizar de la manera correcta la fundamentación normativa del paso de la moral al derecho" (Habermas.jurgen, 2000, pág. 205), desde la ética del discurso es posible construir una teoría del Derecho y de la política, y el eje fundamental de esta construcción teórica es la discusión de lo bueno y de lo justo. Por ello, de acuerdo con Habermas, T. Mc Carthy

fundamenta la necesidad de normativizar jurídicamente las expectativas de comportamiento, especialmente la necesidad de institucionalizar jurídicamente la formación 
de la opinión y de la voluntad de un legislador político, en lo indeterminado del procedimiento discursivo bajo las condiciones de la competencia de diferentes cosmovisiones y de la pluralidad de lenguajes evaluativos (Habermas.jurgen, 2000, pág. 205).

Por lo tanto es importante tener en cuenta que:

Es probable que los desacuerdos [...] sean una característica permanente de la vida pública democrática. Generalmente no se pueden superar mediante soluciones de compromiso estratégicas, el consenso racional o la auto-clarificación ética, en el sentido que Habermas da a estos términos. Todo lo que queda en este esquema son formas más o menos sutiles de coacción, por ejemplo el imperio de la mayoría y la amenaza de sanciones legales (McCarthy, 1992, pág. 210).

De esta forma se puede ver como la moral crea la necesidad de que el Derecho la complemente, o por lo menos eso es lo que McCarthy sostiene cuando precisa que:

Se valga de un argumento que si fuese correcto, tendría que afectar al núcleo mismo de la noción de moral de la teoría del discurso. Ciertamente, también según esa concepción el Derecho coactivo debe compensar las debilidades motivacionales y las indeterminaciones cognitivas del discurso moral basado en la abstracción y la idealización, pero la formación jurídicamente institucionalizada de la opinión y de la voluntad, en la que el Derecho positivo mismo se tiene que legitimar, no se presenta solamente como una red algo compleja de discursos y negociaciones, sino como una alternativa al modelo discursivo (Habermas.jurgen, 2000, pág. 206).

En este punto, toma relevancia hablar de una teoría discursiva del derecho que se articule con la ética del discurso y que permita la validez de los acuerdos sin coacciones. En este contexto, donde podemos analizar la importancia de la propuesta teórica planteada en la ética del discurso.

La idea del Estado de Derecho se puede comprender entonces desde el propósito de institucionalizar jurídicamente los exigentes presupuestos comunicativos y procedimientos de una red de argumentaciones y negociaciones diferenciada atendiendo a las distintas preguntas planteadas. Pues en ese caso es necesario domesticar discursivamente el poder político mismo utilizado para sacar adelante el principio del discurso" (Habermas.jurgen, 2000, pág. 206).

En este orden de ideas McCarthy considera que

con la formación democrática de la opinión y de la voluntad de una sociedad pluralista entra en juego un tercer elemento, el de la coacción legitima, el cual se encuentra formalizado jurídicamente en instituciones reguladas de acuerdo a mayorías (Habermas. jurgen, 2000, pág. 207).

\section{Críticas a la teoría discursiva habermasiana}

Es importante mencionar algunas críticas que se le han formulado al pensamiento Habermasiano, más específicamente en lo atinente al alcance y pertinencia de la ética discursiva en la solución de conflictos sociales. Sobre el particular Bent Fly vbjerg, sostiene que:

El problema es que en una situación no trivial hay pocos criterios claros que permiten determinar lo que ha de ser considerado un argumento, qué tan bueno es, y de qué forma deben compararse entre sí los distintos argumentos. Por supuesto, esto no significa que no se deba tratar de identificar y valorar los argumentos. Pero como ya Bernstein lo mencionó: Toda sociedad debe contar con algún procedimiento para lidiar con los conflictos que no puedan ser resueltos mediante la argumentación-incluso cuando todas las partes se comprometan a sostener una argumentación racional (Flyvbjerg, 2001, pág. 306).

Los aspectos señalados por Flyvbjergno se matizan en la propuesta Habermasiana por su fuerte carga de idealismo; y es en este terreno donde se plantea el debate entre las posiciones de carácter empírico y normativo. Por ello, Agnes Heller y Albrecht Wellmer han criticado la ética discursiva y han dicho que:

Al referirse al principio de universalización de Habermas, antes mencionado, Heller rechaza el valor del punto de vista de Habermas: Dicho en pocas palabras, si buscamos en la filosofía moral una guía para nuestras acciones en el aquí y el ahora, no encontraremos guía alguna en la reformulación habermasiana del Imperativo categórico. Wellmer es igualmente duro cuando dice que adoptar 
el principio de universalización en los juicios morales haría del juicio justificado una imposibilidad [einem Ding der Unmoglichkeit] (Flyvbjerg, 2001, pág. 307).

No obstante lo anterior, hay que decir, que frente a las distintas posiciones que la ética del discurso genera, es importante mencionar:

Que el principio de universalización de Habermas tenga éxito a la hora de obtener de múltiples "yo quiero" un "queremos" depende de que se encuentren "necesidades universalmente aceptadas" El argumento [...] sugiere que esto puede que no sea posible cuando haya divergencias fundamentales en las orientaciones axiológicas. La separación del procedimiento formal respecto del contenido sustantivo no es nunca absoluta: no podemos ponernos de acuerdo acerca de lo que es justo sin obtener algún grado de avenencia acerca de lo que es bueno. Pero el discurso práctico está concebido por Habermas para que se ocupe precisamente de situaciones en las que esa avenencia brilla por su ausencia, a saber, en las que existe la necesidad de regular asuntos acerca de los cuales hay intereses y valores rivales, concepciones del bien que compiten entre sí (Habermas. jurgen, 2000, pág. 207).

Las sociedades modernas se caracterizan por la existencia de una pluralidad de formas de existencia expresadas en creencias, comportamientos, ideologías, religiones, culturas; que aunque se quieran eludir o evitar son necesarias para la convivencia social; en las que surgen proyectos de vida individual y colectiva, que como señala McCarthy citado por Habermas:

Hace cada vez más improbable que en semejantes controversias nos pongamos de acuerdo sobre interpretaciones comunes. Cada vez más raramente podemos recurrir a experiencias y ejemplos plenamente convincentes que tengan el mismo significado para grupos de individuos distintos. Cada vez podemos contar menos con que las mismas razones tengan el mismo peso a la luz de los sistemas de relevancia distintos para individuos y grupos diferentes (Habermas.jurgen, 2000, pág. 208).

Es necesario explicar, al compás de Wellmer que

la conciencia moral posconvencional es el resultado de una visión reflexiva hacia las condiciones de posibilidad de la validez normativa. Este es el punto de partida de la ética discursiva de Habermas y la reformulación del principio moral kantiano. Sin embargo, el principio de universalización Habermasiano, el principio $U$, también es un principio de argumentación. Según Wellmer, es la principal debilidad de esta propuesta, pues al relacionar la justicia a la eticidad paga el precio de la asimilación conceptual de los problemas morales con los legales (Wellmer, 1994, pág. 17) 5 .

Wellmer muestra otros puntos críticos sobre el principio U de universalización que caracteriza a la ética del discurso, es la característica cuasi -circular que contiene y que consiste en la idea de defender normas con pretensiones de universalidad y validez recurriendo al mismo recurso. La crítica de Wellmer se afirmar en que:

La idea de un acuerdo intersubjetivo no es sólo una consecuencia sino también el criterio de fundamentación, de ahí, lo inexplicable de esta postura. Un concepto que se vincula tanto a la fundamentación de la verdad como a la de las normas morales, carece de un presupuesto específico de funcionamiento para la moral, por lo que esta traducción de un plano al otro es, también, muy confusa. Cuando Habermas vincula el proceso de universalización al criterio de validez, caen en un movimiento circular, pues el sentido de la validez moral del deber pareciera desprenderse o ser determinado a priori por un criterio de validez moral del deber (Wellmer, 1994, págs. 18-19).

Como se observa Wellmer le objeta a Habermas su criterio consensual de verdad y alude también a los dos niveles en los que es posible establecer el criterio de verdad de cara al sujeto. Cada sujeto debe convencerse por la vía de argumento si un consenso puede llamarse racional. $\mathrm{Y}$ aunque la verdad sea pública, cada sujeto debe decidir, en cada caso particular, si debiera o no tomar en serio

5 En el principio U, un principio moral universalista es inescrutablemente cambiado con el principio de legitimación democrática de tal forma que lo que fracasa definitivamente es su capacidad de convencer ya sea como principio moral o como principio de legitimación. Este señalamiento de Wellmer ha sido advertido por más de un lector crítico cuando se enfrenta a este problema. Al respecto véase: Seyla Benhabib, critique, Norm and Utopía, Columbia University Press, 1986. Y también a Javier Muguerza, $<<$ la alternativa del disenso $>>$ donde dice: $<<$ Habermas no confunde, según declara el mismo, la ética y el Derecho, pero lo cierto es que los mezcla. 
un argumento (Wellmer, 1994, pág. 18). Agrega el mismo autor que

el criterio de intersubjetividad abre un espectro en donde también es necesario considerar elementos que remiten a la calidad y la forma de reflexión del sujeto, a sus creencias y a sus juicios. Wellmer afirma que en el juicio moral uno se confronta fundamentalmente consigo mismo, y, por lo tanto, llegados hasta ese punto, lo que está en cuestión no es si la norma social es justa o no, sino los otros elementos de la reflexión moral, que nos remiten a las consecuencias y a los efectos que una acción tal podría presentar en caso de su aceptación como norma universal (Wellmer, 1994, pág. 19).

Todas estas críticas se pueden resumir en dos perspectivas, la primera que señala a la ética del discurso de autoritarismo y la segunda de excesivo formalismo. En consecuencia Wellmer considera que:

Sólo podemos deducir la verdad del consenso de su racionalidad, si incluimos, entre sus condiciones para la situación ideal de habla, el requerimiento de que todos los participantes posean una adecuada capacidad para el juicio. Pero si esto es así, ya no podríamos caracterizar las condiciones para una situación ideal de habla en términos formales; y tendríamos que reconocer que tampoco podría incluir a todos los sujetos interesados, pues solo podrían considerarse aquellos que tuvieran capacidad suficiente para ejercitar el juicio (Wellmer, 1994, pág. 20).

Wellmer afirma que la característica de formalidad a la que apunta la teoría consensual de la verdad, busca convertirse en referente en contra del relativismo, y efectivamente lo hace, convirtiéndose en una estructura netamente formal, y dicha estructura formal descansa sobre lo que conocemos como una situación ideal de habla y sobre la que se define el concepto de racionalidad. En este sentido, la crítica a la teoría de Habermas se ubica en el concepto de consenso como verdad y la manera como se llega al mismo. En ese orden de ideas Wellmer insiste en que:

Un criterio del consenso como verdad no puede sino dar pie a dos dificultades: si se le asume dentro de una versión débil, el criterio del consenso fracasa cuando uno admite que todo consenso es provisional y presupone que la revisión conceptual es un proceso infinito. Por otro lado, si se piensa en una versión fuerte, entonces no puede convertirse en un criterio de racionalidad, pues negaría la evolución de la ciencia y su carácter falsable (Wellmer, 1994, pág. 20).

Como se puede inferir del planteamiento critico Wellmeriano, el concepto de consenso como verdad expuesto por Habermas, queda convertido en un aspecto netamente formal y procedimental.

En esta misma línea de trabajo autores como Ernst Tugendhaten considera que:

Habermas afirma que la verdad, o la fundamentación de la verdad, deben entenderse como algo esencialmente comunicativo. Naturalmente, la vinculación entre verificación o fundamentación por un lado, y acuerdo intersubjetivo por otro, es tradicional e indiscutible. Lo sorprendente de la concepción de Habermas es que, según ella, el acuerdo intersubjetivo no debe ser la consecuencia, sino el criterio de fundamentación de un enunciado (Tugendhat, 2002, pág. 130).

Para Tugendhat este procedimiento cuando se aplica a los enunciados empíricos es totalmente falso y por tanto considera que:

El criterio de fundamentación de las proposiciones enunciativas empíricas está contenido en las reglas de verificación que constituye su significado. Verdad y justificación son conceptos semánticos. La aplicación de las reglas relevantes no tiene un carácter constitutivamente comunicativo. $\mathrm{Y}$ el hecho de que diferentes personas, al fundamentar así una proposición, lleguen a un acuerdo, se basan simplemente en que aplican las mismas reglas de fundamentación. La concepción opuesta, a resultas de la cual es el propio acuerdo el criterio de fundamentación, está expuesta a la objeción de que el acuerdo fáctico no puede ser normativo, sino sólo un acuerdo cualificado (Tugendhat, 2002, pág. 130).

Tugendhat emite sus propias objeciones frente a Habermas en lo concerniente al procedimiento construido para la validez de los acuerdo; frente a lo cual Habermas se defiende de los cuestionamientos de Tugendhat y argumenta que su planteamiento teórico alrededor del procedimiento argumentativo que se requiere para alcanzar los acuerdos que tengan pretensiones de validez, lo 
Justicia Juris, ISSN 1692-8571, Vol. 11. Nº 1. Enero - Julio de 2015 Págs. 125-139

hace desde las reglas de la comunicación que son propiamente discursivas. Pero además Habermas agrega que:

Nunca ha indicado en qué consisten tales reglas, y dudo que existan. Es cierto que la historia de la ciencia empírica es un proceso comunicativo, pero donde hay en este proceso desarrollos que sólo pueden ser considerados resultado de un acuerdo, se trata de desarrollos que no están determinados por reglas y no pueden ser fundados racionalmente. Se delinea así una situación con un perfil que se vuelve aún más nítido en el ámbito de la moral, a saber: hasta donde llega una justificación mediante razones [Grunde], permanecemos en la dimensión semántica $\mathrm{y}$, tan pronto como aparece algo irreductiblemente comunicativo, no se trata ya de una cuestión de argumentación, sino de decisión, no tiene ya un carácter cognitivo, sino volitivo (Tugendhat, 2002, pág. 131).

Habermas defiende la cualificación de los acuerdos desde los procedimientos formales establecidos para ello, que permite la racionalidad de los mismos. Además, pretende mostrar otra forma de cualificación de los acuerdos, para ello, se vale de la distinción entre lo que es un acuerdo racional y un acuerdo irracional y las condiciones de racionalidad o irracionalidad que están determinadas por una situación ideal de habla, que no es otra cosa, que condiciones de simetría entre individuos o grupos humanos que dialogan con el fin de construir acuerdos que tengan el consenso y la validez necesaria para ser aceptados por el mayor número de personas o por lo menos a quienes se involucran en un ejercicio dialógico.

Tugendhat continúa con sus objeciones a la teoría del consenso argumentativo de Habermas afirmando que:

La teoría del consenso es inaceptable como teoría general de fundamentación. Pero la fundamentación de las normas constituye una situación particular -al menos en el caso especial en que el criterio de su fundamentación debe consistir en la posibilidad de que todos las aceptemos racionalmente. Mientras que en la fundamentación de una convicción teórica el acuerdo es una mera consecuencia, es indudable que en la fundamentación de una convicción moral -en cualquier caso si la fundamentación se entiende de este modo- sí entra un acuerdo en el mismo procedimiento de fundamentación (Tugendhat, 2002, pág. 132).

Tugendhat afirma que el acuerdo fáctico planteado por Habermas, es un acuerdo cualificado y con ello, lo saca del plano de lo que es un acuerdo normativo; que es el argumento principal defendido por Habermas. A estas objeciones, Habermas le ha dado respuesta, pero Tugendhat insiste en que dichas explicaciones son insuficientes. En consecuencia, de lo que se trata es de mostrar que el procedimiento de fundamentación sería más pertinente y acertado sino fuera hipotético. En esto consisten unos de los cuestionamientos de Tugendhat a Habermas.

\section{Ahora bien, para Tugendhat:}

El motivo por el que esto parece dudoso es, obviamente, porque aquí se tiene que preguntar también lo siguiente: el acuerdo de que se trata, ¿es sólo el acuerdo efectivo (de todos los implicados), o debe estar cualificado de un modo determinado? Para mí está claro que tiene que ser cualificado, pero de modo diferente que en el anterior. Allí sólo contaba el acuerdo que se basaba en el respeto a las reglas de fundamentación; aquí cuenta sólo aquel acuerdo que se compone de las dos fases en que se define esta concepción de la moral: cada cual ha de preguntarse a sí mismo si puede estar de acuerdo con la validez general de la norma con relación a su bien [-estar: Wohl (T)], sólo valiendo este consenso como consenso racional; y, en segundo lugar, debe conceder a todos los demás el mismo derecho, pero nada más; es decir, que cuando tiene lugar un discurso real sobre la fundamentación de una norma, los participantes no pueden hacer valer simplemente sus intereses, sino que en su discurso deben ya partir de la idea de imparcialidad; esta idea no es el resultado, sino el presupuesto de un discurso semejante (Tugendhat, 2002, págs. 133-134).

Habermas ha admitido esto al asumir "como regla de la situación ideal de habla la condición de que exista una simetría entre los participantes no sólo en lo referente a las oportunidades de hablar, sino con respecto a sus oportunidades de actuar, a sus derechos de "ordenar y de oponerse" (Tugendhat, 2002, pág. 134). Para Habermas la comunicación tiene la característica de imparcialidad y que para Tugendhat, lo que muestra es que no la puede fundamentar, y presupone entonces "simplemente que la fundamentación de las normas consiste 
en fundarlas como igualmente buenas para todos, pero entonces se trataría de un presupuesto semántico con respecto al predicado de fundamentación, presupuesto en el que funda exclusivamente, a su vez, el hipotético discurso ideal" (Tugendhat, 2002, pág. 134). Aquí, se encuentran planteadas las objeciones de Tugendhat a Habermas y la defensa que hace Habermas de su teoría discursiva y que básicamente están formulados en dos aspectos; el primero que hace referencia al presupuesto de imparcialidad, como un presupuesto de fundamentación que es igualmente bueno para todos. El segundo aspecto de esta discusión es que el principio de imparcialidad como presupuesto de fundamentación es esencialmente comunicativo.

En este sentido, los actos de habla expuestos por cada uno de los miembros de la comunidad son fuente de información y en consecuencia el proceso de fundamentación no ha sido propiamente comunicativo. En este orden de ideas Tugendhat considera que este es un procedimiento normal

porque pensamos que las personas implicadas tienen que decidir las normas bajo las cuales han de vivir; me parece claro que no se trata de una necesidad que resulte de la regla de fundamentación, sino de "un tener que" en el sentido moral. Hasta que sólo se trataba de aproximarse a un resultado lo más justo posible, con los mejores motivos posibles (Tugendhat, 2002, pág. 136).

Esta norma es continuación del principio moral aquí expuesto, de que sólo está fundamentado aquello a lo cual todos pueden asentir racionalmente.

De esta manera podemos inferir, que ninguna persona racional, capaz de reflexionar, estaría de acuerdo en que se le impidiera decidir personalmente lo que es bueno para sí; naturalmente puede pedir consejos a otros, pero estará dispuesta a correr el riesgo de equivocarse decidiendo qué cosa sea buena para él, antes que dejárselo imponer por otros (Tugendhat, 2002, pág. 136).

Se pone de presente el principio de la autonomía, en el sentido de decidir por nosotros mismos, al estilo de la mayoría de edad Kantiana. En este orden de la discusión, el profesor Tugendhat considera:

Esta norma que deriva de un principio de la moral racional en sentido estricto y que ordena considerar a toda persona como ser autó- nomo que decide por sí mismo -y por tanto prohíbe dictarle qué es lo bueno para ella- tiene por consecuencia que, allí donde sea preciso decidir con respecto a una norma social-en particular,, sobre una norma jurídica-, la introducción de esta norma sólo está moralmente justificada si es fruto de una deliberación colectiva en la que participen todas las personas interesadas. Puede llamarse principio de la autonomía colectiva o de la autodeterminación colectiva (Tugendhat, 2002, pág. 137).

Lo que este principio niega es la inhabilitación moral del colectivo. En este sentido, no es correcto que un individuo o un grupo de individuos acudan a su superioridad intelectual o moral para determinar que norma o normas jurídicas deben imponerse o tener mayor validez, desconociendo la participación de los otros individuos implicados en tal discusión. Por ello, es necesario reafirmar una vez más, la necesidad de que en la discusión de los asuntos morales, políticos y jurídicos, deben fundarse ineludiblemente en la participación y discusión de todos los involucrados. Contrariamente a la opinión de Habermas, para quien

el motivo no es la naturaleza comunicativa del proceso de fundamentación moral, sino al revés: una de las reglas que resultan del proceso de fundamentación moral -que, como tal, puede realizarse también en el pensamiento solitario- prescribe que sólo están fundadas moralmente aquellas normas jurídicas que se han introducido sobre la base de un acuerdo de todas las partes implicadas (Tugendhat, 2002, pág. 138).

Esto muestra claramente la necesidad de la construcción de acuerdos y consensos por medios comunicativos, mediados por el respecto a la autonomía moral de cada uno de los involucrados.

Para Tugendhat, en este punto de la discusión surge un problema, y es

plantear que no se trata de un asunto de fundamentación, o mejor que no se trata de un problema de fundamentación, sino del problema de la participación en el poder que decide qué es lo legalmente permitido y lo que no. La idea de una ética comunicativa concebida por Habermas debe entenderse en conexión con la idea de democracia y con la exigencia de una extensión de esta idea a todos los sectores de la sociedad, con la exigencia de participación (Tugendhat, 2002, pág. 139). 
Justicia Juris, ISSN 1692-8571, Vol. 11. Nº 1. Enero - Julio de 2015 Págs. 125-139

En este punto de la discusión, Thugendhat critica fuertemente a Habermas, al considerar que:

Ha confundido el discurso hipotético con el real, que le ha llevado a descuidar el factor volitivo y, con él, el problema del poder. Ha pasado por alto el hecho de que la argumentación moral hipotética en general no es esencialmente un discurso real, algo realmente comunicativo, y por ello -porque su uso del término $<<$ discurso $>>$ ha obviado la distinción entre esta argumentación moral comunicativa hipotética y un discurso realmente comunicativo- ha podido no tener en cuenta aquel aspecto no racional y volitivo del discurso real que exige la moral (Tugendhat, 2002, pág. 139).

La fundamentación de nuestras convicciones morales no es un proceso eminentemente comunicativo, sino que también contempla procedimientos de carácter participativo que son determinantes en la toma de decisiones; que excluye formas y relaciones de poder unidimensionales; este sería la forma posible en un escenario de imparcialidad o universalidad. El profesor Tugendhat tiene la impresión de que Habermas "piensa además que, en general, sólo llegamos a la idea de imparcialidad mediante un proceso comunicativo; $y$, en efecto, si debe quedar algo todavía de una fundamentación esencialmente comunicativa, esto sólo puede estar aquí" (Tugendhat, 2002, pág. 140). De esta manera, es necesario indicar que Habermas ha defendido la tesis de que las condiciones comunicativas en las que se polemiza sobre las convicciones morales, requiere de una situación ideal de habla. Y es en esta situación ideal de habla, donde debe estar ya presupuesto todo lo que debería ser fundado, es decir, lo que debería ser fundamentado como resultado de un ejercicio comunicativo.

En consecuencia, se puede afirmar que existen dos grandes críticas contra la teoría discursiva de Habermas y más específicamente sobre la ética del discurso; la primera señala a la ética del discurso de estar cargada de un fuerte autoritarismo y la segunda de que posee un fuerte formalismo. A continuación se tratará de analizar estas críticas, cada una por separado, para tratar de comprender los argumentos que se han dado sobre un lado y el otro.

Los que se inclinan por la concepción, de que la ética del discurso es autoritaria; consideran que el enfoque del consenso racional, genera una supresión de las formas de vida independiente y en consecuencia de la sociedad civil; de este modo la acusación de autoritarismo tiene diversas variables. La primera implica una aplicación general de la crítica de Hegel a Kant, que relaciona la moralidad abstracta y el terror con la ética del discurso como un todo. En este nivel, la objeción ha sido refutada con éxito por Albrecht Wellmer (Cohen, 2000, pág. 409).

Es así, como Habermas "descubre un potencial autoritario en dos conjuntos particulares de distinciones: 1) entre el consenso "empírico" y el "racional", y 2) entre los intereses "particulares" o "generales". Según Robert Spaeman, por ejemplo, con estas distinciones "el objetivo utópico" de abolir la dominación sirve precisamente como legitimación de la dominación por parte de los "ilustradores" "auto designados" (Cohen, 2000, pág. 409).

Habermas le apuesta a la construcción de consensos racionales, por encima de los empíricos. Además, a la técnica del discurso como mecanismo que hace posible construcción de los acuerdos como verdades.

La consecuencia del argumento de Habermas, en otras palabras, no es la de remplazar forzosamente la condición de un tipo de discurso con la de otro, sino establecer nuevas formas lado a lado con las antiguas y, quizá, revitalizar las formas existentes de la vida pública. En realidad, Habermas niega explícitamente un discurso privilegiado de intelectuales o de organizaciones políticas que desempeñarán un papel principal respecto a los procesos empíricos de la comunicación (Cohen, 2000, pág. 409).

La ética del discurso somete a contrastación la validez de las normas, ya sea en el plano del interés particular o colectivo. Habermas "sostiene que la ética del discurso introduce interpretaciones de las necesidades en las discusiones de las normas, de modo que un consenso libre de limitaciones permite sólo lo que todos pueden desear" (Habermas j. , 1999, pág. 89). Siempre y cuando las normas expresen intereses que puedan ser generalizables y que sean producto de un acuerdo general; solo así, alcanzarían el consenso y la legitimidad.

Por ello, Habermas "ha recurrido repetidamente al lenguaje condicional de la atribución; estaría de acuerdo si ellos ingresaran en un discurso sin restricciones" (Habermas j. , 1999, pág. 89). Esto muestra que los interés generalizables, deben ser descubiertos a través de los procesos discursivos; son estos procesos los que develan y hacen expli- 
cito los saberes implícitos de los sujetos de manera práctica. Y mientras, esos interés no se expresen comunicativamente; aparece lo que podríamos llamar intereses suprimidos, en este punto, se acusa a Habermas de autoritario. Habermas

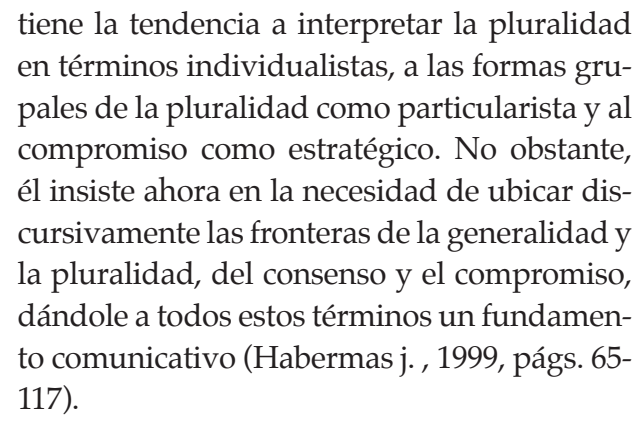

Es entendible que en un proceso discursivo, existan esfuerzos tendientes al logro del interés común y otros esfuerzos tendientes al logro de compromisos que superen los conflictos entre particulares. En estos dos tipos de procesos discursivos, independiente al telos que se persiga; requiere de una estructura normativa implícita en los procesos discursivos.

\section{Conclusión}

En consecuencia, Habermas sostiene "que podemos dar bases racionales para un reconocimiento intersubjetivo de las pretensiones de validez sin recurrir a la metafísica o al dogmatismo" (Cohen, 2000, pág. 414); por cuanto, las pretensiones de validez de las normas están soportadas en el reconoci- miento de las mismas normas. Por ello, Habermas insiste afirmando que el componente cognitivo de las normas no se limita al contenido propositivo de las expectativas de conducta normada.

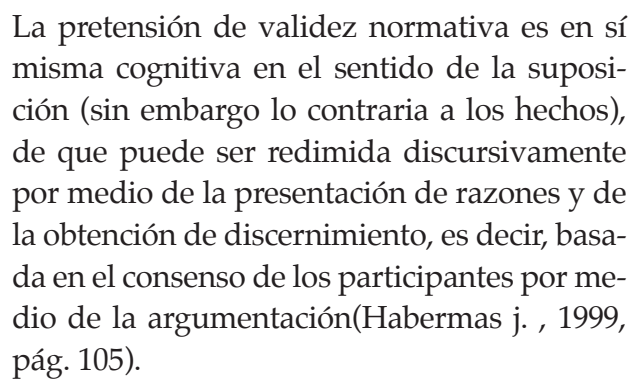

De esta forma, queda demostrado en qué consiste el concepto de racionalidad, y como a través de principios de argumentación de carácter cognitivo se puede llegar a la construcción de acuerdos.

En este contexto de la legitimidad política, la ética del discurso aporta elementos con los cuales, escoger aquellos aspectos de nuestra tradición cultural, de identidad colectiva y de cultura política; es decir, todos aquellos aspectos de nuestras costumbres y que intentamos preservar y mantener y en el que reposan las características necesarias para el surgimiento de normas legitimas. Lo anterior muestra que de la forma como nos ponemos de acuerdo para construir legitimidad alrededor de una forma de poder-autoridad de carácter político; de igual forma, es posible en las sociedades civiles modernas participar en la resolución de conflictos de manera discursiva.

\section{Referencias}

Cohen, J L. y Arato,A(2000). Sociedad civil y teoría política. México: Fondo de Cultura Económica.

Crespi, I. (2000). El proceso de opinión pública. Cómo habla la gente. Barcelona: Ariel.

Cortina Orts, A (1985). La hermenéutica crítica en Apel y Habermas. Estudios Filosóficos 34.95: 83-114.

García Amado, J (1999). La filosofía del derecho de Habermas y Luhmann. Bogotá: Universidad Externado de Colombia.

Habermas, J (2002). Acción comunicativa y razón sin trascendencia. Barcelona: Paidós. 
Justicia Juris, ISSN 1692-8571, Vol. 11. Nº 1. Enero - Julio de 2015 Págs. 125-139

Habermas, J. (2000). Aclaraciones a la ética del discurso. Madrid: Trotta.

Habermas, J. (2000). Conciencia moral y acción comunicativa. Barcelona: Península.

Habermas, J. (2009). El Occidente escindido. Barcelona: Trotta.

Habermas, J. (1999). Legitimación y crisis. Madrid: Cátedra.

Habermas, J. (1998). Más allá del estado nacional. Madrid: Trotta.

Habermas, J. (2010). Ciencia y técnica como ideología. 7a. ed. Madrid: Tecnos.

McCarthy, T. (1992). El discurso práctico: sobre la relación de la moralidad con la política. Madrid: Tecnos.

Micheleini, O. (1991). Ética discursiva y legitimidad democrática. Barcelona: Crítica.

Tugendhat, Ernst. (2002) Problemas de la ética. Barcelona: Gedisa.

McCarthy, T. (1993). La pragmática de la razón comunicativa. Isegoria 8 (1993): 65-84.

Flyvbjerg, Bent. (2001) Habermas y Foucault. ¿Pensadores de la sociedad civil? Estudios Sociológicos 9.002 (May. Ago., 2001): 307.

Suárez, J. Syllabus sobre filosofía política. Medellín: Universidad Pontificia Bolivariana. 